$\xi$

\title{
The Dynamics of Various Networks in Transnational Entrepreneurship and Study on Negative Factors to Enterprise among Immigrant Indian Entrepreneurs in UK - a Working Paper
}

\author{
N.Gangadhar $^{1 *}$, B. M. Manohar ${ }^{2}$ \\ ${ }^{I}$ VIT Business School, VIT University, Vellore, Tamil Nadu, India \\ ${ }^{2}$ VIT Business School, VIT University, Vellore, Tamil Nadu, India \\ *Corresponding author E-mail: nithyal.gangadhar@gmail.com
}

\begin{abstract}
Transnational entrepreneurship has attracted a lot of interest from scholars around the world. The purpose of this paper is to investigate the factors that affect the internationalization of emerging transnational entrepreneurs in UK. This paper has considered only the entrepreneurs who are first generation immigration entrepreneurs who maintain business base in their home country and established a trading relation in the host country. The study focuses on the field of transnational entrepreneurship by proposing an exploratory study on Transnational Enterprise by defining the importance or relevance of different kinds of networks and also to explore the possibilities of negative factors such as bad experiences, dissatisfaction or negative perceptions of their host country, to be an inspiration to venture into transnational entrepreneurship.
\end{abstract}

Keywords: diaspora, glocalised networks, immigrants, Indian entrepreneurs, transnational entrepreneurs.

\section{Introduction}

The concept of Transnational Entrepreneurship was inspired from the concept of migration and looked at from a different angle. It was first studied in the 20th century by anthropologists and sociologists, (Portes, et al., 2002), but afterwards becomes increasingly important for the economists due to its vested interest in the area of international business (Brzozovski, et al., 2014). Transnational entrepreneurship is a phenomenon that became more prominent in recent years due to revolution in the field of digital communication and affordable transportation systems which make it possible for the immigrants to travel frequently across countries and continents. Transnationalism places limelight on the economic and social connections between the different nations and the changes it brings across.

Much like multinational corporations, transnational entrepreneurs started exploiting opportunities between multiple countries, while keeping their home countries as a base and often expanding their business to a new market or creating a venture in another country based upon their existing networks and resources available to them. All the way through the history of immigration, immigrants have stayed in contact with families, organizations and communities in their places of origin from the host countries. The growth and development of internet and technology has led to the phenomenal development of transnational business as it gives the advantage of visibility to global customers (Windsor, 2015). Transnational entrepreneurship refers to those ventures in which an individual emigrates but still maintains economic linkages with his home country (Light 2007; Portes 1995; Saxenian 2002; Saxenian and Hsu 2001). Nicholas Li (2002) in his study on
Chinese transnational entrepreneurs explains that Transnational entrepreneurs embark on the task of international entrepreneurship by identifying international opportunities, exploiting, accumulating resources and delivering innovative products and services, and strive for success while maintaining balance between both the host and the home countries. According an initial research on international entrepreneurs, it was observed that 37.5$78.5 \%$ of migrant entrepreneurs fall into the category of transnational entrepreneurs, based on their ethnic group and the location (Portes et al.2002).

Yeung (2002) opines that “...transnational entrepreneurs not only learn how to deal with unexpected contingencies in the host countries, but also develop a deeper understanding of the realities of these host countries." It is observed that the migrant entrepreneurship excels in the host country; the entrepreneur would consider it possible to extend its activities to other geographical locations as well provided the home country or the country of origin provides social capital, economic resources and cultural adaptability. Enhanced transnationalism is significantly transforming the entrepreneurial practices through changed political social, and economic structures and practices among immigrants through the world (Vertovec 2004a).

Most of the research on transnational entrepreneurs has been predominantly published in US (Wang and Liu 2015) and Canada (Lin and Tao 2012). Although closely associated with international entrepreneurship, transnational entrepreneurship is identified as an emerging topic of research (Drori et al,2009). However, surprisingly there is a dearth of research in the area of migrant entrepreneurship and transnational entrepreneurship in terms of identifying the determinants and dynamics of the immigrant Indian entrepreneurs in UK. This research paper seeks 
to fill this gap by gaining insights into the ventures of first generation transnational entrepreneurs.

\section{Theoretical Discussion:}

Transnational entrepreneurs are migrant business owners, traveling abroad for business purposes and engaged in business activities, based on ties to a foreign country. Although operating in two or more countries exposes the entrepreneur to more sources of information and can increase the ability of the entrepreneur to make connections and discover opportunities, it also must surmount institutional constraints of two or more localities (Yeung,2002).

As defined by the authors, Transnational entrepreneurs were the subset of firm-owners who travelled out of the country at leas twice a year for business and their success depended on the regular business interactions with their home countries. Human capital, in the form of years of education and high occupational skills, has been observed to play a significant role in immigrant business success. Social networks also play a very pivotal role in the process of immigrant adaptation. Those with more diverse social networks will be in a better position to instigate and uphold transnational enterprise. The social connections in which particular immigrant flows are ingrained can also affect their economic options (Portes et al, 2002).

Transnational Entrepreneurship (TE) has to adopt a frequency of travel between the host and home country. The process of TE refers to activities carried out by entrepreneurs who are entrenched in at least two or more different economic and social locations. They have to widen their capabilities and increase their understanding and operating in multiple institutional environments. Transnational Entrepreneurial activities have to acclimatize to the institutional relations, policies and political arenas in both home and host countries. TE should make use of industry networks that cross the geographical boundaries and provide access to key resources, like personnel, working opportunities, information and potential clientele. TE also makes use of social capital that provides them resources and "access to those social and economic features that facilitate their plight for founding, retention and surplus production". Thus, the transnational embodiment that is marked by dual association and orientation, is affiliated with a variety of social experiences and practices that facilitate the discovery enactment and exploitation of business opportunities while considering the national culture and local institutions during the internationalization process.(Drori et al 2006)

Sequira et al (2009) define Transnational Enterprise as "a business in the ethnic economy which entails separate operational components of the enterprise being located in different countries and the transmigration of the owners in order to operate it". The authors describe the Transnational Entrepreneurs (TEs) as overseas born, self-made business people who engage in activities that require frequent travel to different countries. The possibility of success of their business ideas depends on their social and business contacts and associates, primarily in their home country. These entrepreneurs are distinctive as they are socially rooted in both their home and host countries, which allows them access to people, business networks, and/or national resources in both environments. Like the earlier authors like Drori et al (2006) even they observed that these resources help these entrepreneurs in opportunity identification, innovative start-up, and maintenance of new ventures.

According to Drori et al. (2009), TEs are social beings who have come with an intention to promote their entrepreneurial endeavours through their networks, and connections, use their ideas, information, and proven practices for the purpose of seeking business opportunities or sustaining the existing businesses within dual social fields and enact with varied strategies of action. TE activities cope and adapt to the institutional relations in both home and host countries by "the social and business networks, in which these TEs are embedded, political-economic structures, and dominant organizational and cultural practices in the home and host countries. The choice of strategy and action on the resources available; these resources include, e.g., symbolic and material resources, professional knowledge and skills, cultural capital, and a social position within an organization, as well as within communal, familial, and other settings".(Drori et al, 2009)

The existing literature commonly tends to relate transnationalism with migrants with low income and with lower educational background; however, exceptions can be found. Personal acquaintances, business cross-border networks, and the sociopolitical associations of the TEs provide the data, supportive resources, and infrastructure necessary for successful transnational activities. Transnationalism has focused on individuals, their host and home communities, their networks of social and cultural relations, as well as local and national governments. Seeking to understand the motives of entrepreneurs, recent literature differentiates between the "necessity" type who is pushed into entrepreneurship because other options are absent or unsatisfactory and the "opportunity" type who is pulled into entrepreneurship by novel business opportunities.(Bagwell, 2014) It was found that the motivation to start a venture in the host country ranged from "transnational activities as a response to various negative factors, among them discrimination, negative experiences, dissatisfaction with their lives, social status or occupational careers, and/or negative perceptions of their host country. TE is culturally oriented, culturally derived, and reliant on the specific community and relationships within which the immigrant is embedded" (Sequeira et al, 2009). The role of TEs in international trade specifically exports, has exponentially increased over years.

TEs have been viewed as a part of a diaspora, though originally used in religiously terms, means people who have spread or been dispersed from their homeland. TEs tend to rely on support from members of the diaspora in many different countries, not just home country. With the advancement in transport and communication, there is less of a need for the owner to travel back and forth between host and home country or countries. Transnational activity is not only been conducted solely between the host and home country but could involve other countries within the diaspora. TE can make use of "glocalised" networks in order to provide competitive advantage. (Bagwell,2014)

Research also has identified age as one of the important predictor for TE (45>). The feasible opportunities in the transnational area could be a prime reason for the immigrants to undertake an entrepreneurial venture, drawing resources from dual locations. Business opportunities and economic success overshadow the home country sentiments. It has been observed that the host countries who support transnational ventures benefit from enhanced innovative performance. TEs can help break cultural and linguistic boundaries and facilitate access to sources in the TEs' origin countries. (Lin and Tao, 2012)

Institutional factors in both host and home societies have a great impact on the possibility of establishing economic linkages. Immigrants may evolve towards transnational activities as a response to various negative factors such as bad experiences, dissatisfaction or negative perceptions of their host country. Entrepreneurs who move to host country for negative institutional reasons such as unemployment, bad economic conditions or failure in their personal or business projects disregard the opportunity to create a firm in the home country because they consider they can increase their wealth in a more stable and better institutional context. A positive experience in the host country due to a successful employment career and a good settlement of immigrants may lead to fewer linkages with the home country. An open mind, a creative and futuristic planning will allow immigrant entrepreneurs to detect more opportunities and compete in a massive market and thus increase the probability of growth and survival. Greater tolerance towards immigration and cultural 
similarities have a positive impact on the perception of business opportunities in the home and host economy.(Baltar and Icart, 2013)

Networks are another important factor or determinant because they are crucial sources required for the acquirement of sparse resources such as investment and knowledge. Entrepreneurship can be either successful or unsuccessful depending on the individual entrepreneur's understanding on the current context or the action strategies on which decisions are based. Due to the novelty in the business ideas, they tend to take risk and plunge into different business in the newly emerging markets on the basis of their connections with their home country and the host country. Based on their knowledge of local political, economic and cultural state of affairs in both the countries, migrants-entrepreneurs have an edge and can snowball their way to other investors and employers in the country of origin (Pavlov et al, 2013).

The international networks that associate an immigrant to the home country is one of the important source of the economic success and competitive advantage of TEs. Transnationalism enforces that a better understanding of culture, language and markets of the home country and the host country can be applied as a competitive advantage to advance transnational practices. The TEs stick out with their unique business idea, with them fully reliant on the dual institutional and cultural environment, to cater to the potential customers with their products and services (Rogerson and Mushawemhuka, 2015). These cultural and ethnic characteristics of the home country networks are major drivers which makes some immigrant groups more entrepreneurial than others. Crucial resources as information, local knowledge, capital, market and technology can be acquired/accessed and enabled through the cross-border networks. However, the acquired resources can have only limited relevance on the development of the TE firms, as the performance of the transnational networks depends on the home country characteristics. Especially when the home-country institutional socio-economic characteristics (such as macroeconomic stability, the level and quality of education, level of corruption and level of the entrepreneurial endowment) and entrepreneurial attitude (uncertainty avoidance, long-term orientation, the locus of control and need for achievements) are taken into consideration. It helps in explaining the differential impact of ties-performance relationship. The human capital in the home country is also another important determinant, as it activates the business opportunities, which otherwise wouldn't exist and also accelerates the capital accumulation helping TEs to become the source of seed capital for business initiatives back in their home countries (Brzozowski, 2014).

The most critical distinctive feature of TEs of bifocality or the ability to function and cater across two different business markets provides TE, the opportunity to "commercialize a business idea across multiple institutional settings". Networks play a critical role for the success of TEs to concurrently maintain business-related linkages with their country of origin, and adopted countries and communities. TE must be considered as "a distinctive attribute of globalization" and indivisible from the changing character of international migration. (Rogerson and Mushawemhuka, 2015). Transnational entrepreneurs (TE) are able to identify and grab new business opportunities and act swiftly to shift the production across borders. This gives them a competitive advantage to grow over their counterparts, immigrant entrepreneurs (IE) and native entrepreneurs (Levie and Smallbone, 2009).

\section{Observations from the Literature:}

Most of the study on TE, observed homogeneity which may have resulted in overwhelming studies on the either the immigrant entrepreneurs thriving in the ethnic commune or a particular elite community of entrepreneurs involved in business activities in the host country targeting foreign investors. Main reasons for these diverse characteristics of transnational entrepreneurship might be because of the samples selected by the researchers in most of the studies. The studies are most commonly found in a few concentrated immigrant groups - mostly on the Latino communities (Landolt et al., 1999; Portes et al., 2002; Sequeira et al., 2009) and Chinese communities (Wong and Ng, 2002; Lin and Tao, 2012) and the studies are very selective in host countries typically the US and Canada. It is also observed that the transnational entrepreneurship is pursued and better managed by educated and older migrants than immigrants who have been in the host country longer, hence justifies its business advantages as an alternative form of immigrant economic adaptation.

The studies show that the immigrants generally tend to blend in the host country by adapting to the ethnic culture of the host country, which the authors define as the "transnational paradigm", proposed primarily by anthropologists and sociologists, which showcases that the immigrants as the active actors of the integration process, (Schiller et al., 1992; Foner, 1997; Vertovec, 1999). But in case of TE, the entrepreneurs try to maintain or preserve their ethnical background and work towards getting their culture, through products and services to the host country and hence, the gradual attrition of their ethnic identity to the benefit of a new one, ie., the adapted identity, connected to the host country, will not essentially take place. Hence, this notion is challenging the assimilation model, which defines that the immigrants tend to gradually adapt into the host country cultural norms and social environment (Gordon, 1964). TE thrives on dual identities (of the home and host countries) instead of blending in to ethnic identity of the host country, at the expense of the former one. Keeping the cultural identity of the home country, intact is one of the strengths/secrets of success of TE.

The above analysis of the literature suggests that, the following are the predominant determinants of a Transnational Entrepreneurship and the factors that influence the expansion of transnational entrepreneurial engagement in home and the host country:

1. Networks (Rogerson and Mushawemhuka, 2015, Pavlov et al, 2013, Brzozowski, 2014, Portes et al, 2002).

2. Human capital, in the form of intellectual skills and high occupational skills (Portes et al, 2002)

3. Extensive and diverse socio-political connections that support these entrepreneurs in opportunity identification, start-up, and upholding of new ventures. (Portes et al, 2002)

4. Symbolic and material resources, professional knowledge and skills, cultural capital, and a social position within an organization, (Drori et al, 2009)

5. Industry networks that provide access key resources, like personnel, working opportunities, information and potential clientele.(Drori et al 2006)

6. Capabilities in perceiving and operating in multiple institutional environments. (Drori et al 2006)

7. The institutional relations, policies and political arenas .(Drori et al 2006)

8. Personal and business cross-border networks (Sequeira et al, 2009).

9. "Glocalised" networks in order to provide competitive advantage. (Bagwell,2014)

10. Age (Lin and Tao, 2012)

11. Feasible opportunities in the transnational area (Lin and Tao, 2012)

12. Negative factors such as bad experiences, dissatisfaction or negative perceptions of their host country. (Baltar and Icart, 2013)

13. Cultural and ethnic characteristics of the home country networks (Brzozowski, 2014)

14. Bifocality or the ability to work and thrive across two different business environments (Rogerson and Mushawemhuka, 2015) 
Due to the absolute volume and vastness of the parameters identified, we would be restricting our study to certain determinants, to get into an initial understanding of the transnational entrepreneurs of Indian origin in UK. We will be focusing mainly on the first generation entrepreneur, as that would give us a complete pulse of how it is establish a business in a host country keeping the ethnic background intact. Hence in our study, we propose the following Objectives:

1. To interpret the internationalisation patterns of Transnational Enterprise through qualitative case studies

2. To propose an exploratory study on Transnational Enterprise by defining the importance or relevance of different kinds of networks - cultural and ethnic characteristics of the home country networks, glocalised networks, industry networks, personal acquaintances, business cross-border networks, and the socio-political associations

3. To explore the possibilities of negative factors such as bad experiences, dissatisfaction or negative perceptions of their host country, to be an inspiration to venture into transnational entrepreneurship.

\section{Guidelines for the Study:}

In our study, we would be focusing on immigrant entrepreneurs of Indian origin in UK, particularly in the city of London. As of now, we are not restricting our study to any particular sector, as we found that there is dearth of research in the area of transnational entrepreneurship in UK. The study that has been carried out on UK on transnationalism has seldom touched the Indian entrepreneurs except for a few mentions in the context of immigrants in general. (Li 2014; Windsor,2015; Quirke et al, 2009;). Since the study is exploratory in nature, we would be adapting case study method, which would give an advantage of producing a qualitative approach to explore the respondents in depth. We would be adapting a snowballing method for the sample selection, as we reckon that it would be the best way to identify relevant respondents for the study. The study would be adopting a detailed analysis of the one on one interview and doing a content analysis to understand the intricacies of the information provided by the respondents.

\section{References}

[1] Bagwell S,( 2014) "Transnational Entrepreneurship amongst Vietnamese Businesses in London", Journal of Ethnic and Migration Studies, Vol.41(2), p.329-349,

[2] Baltar, F. and Icart, I (2013), "Entrepreneurial gain, cultural similarity and transnational entrepreneurship", Global Networks, , Vol.13(2), pp.200-220,

[3] Brzozowski J, Cucculelli.M and Surdej A (2014), "Transnational ties and performance of immigrant entrepreneurs: the role of homecountry conditions", Entrepreneurship \& Regional Development, Vol.26(7-8), p.546-573.

[4] Drori I, Ginsberg A, Honing B (2006), "Transnational Entrepreneurship: Toward a Unifying Theoretical framework", Academy of Management Proceedings, Vol.2006(1), pp.Q1-Q6.

[5] Drori I, Honig B, Wright M, (2009) - "Transnational Entrepreneurship: An Emergent Field of Study”, Entrepreneurship Theory and Practice.

[6] Foner, N. (1997), "What's new about transnationalism?: New York immigrants today and at the turn of the century." Diaspora: A Journal of Transnational Studies 6.3 (1997): 355-375.

[7] Landolt Patricia, Lilian Autler, and Sonia Baires (1999) "From hermano lejano to hermano mayor: the dialectics of Salvadoran transnationalism." Ethnic and Racial Studies 22.2 (1999): 290 315.

[8] Levie, J.D. and Smallbone, David (2009), "Immigration, ethnicity and entrepreneurial behaviour in: Perspectives on Entrepreneurship", Volume 1. Praeger Publishers, pp. 157-180.
[9] Light, I (2007), "Global entrepreneurship and transnationalism, In L.P. Dana (Ed.)", Handbook of research on ethnic minority entrepreneurship, Cheltenham, U.K.: Edward Elgar, , (pp. 3-15).

[10] Li N, (2014), "The Internationalisation of Chinese Transnational Entrepreneurial Firms: A comparative study with indigenous counterparts in Canada and UK", University of Glasgow, UK

[11] Lin, Xiaohua, and Tao S (2012), "Transnational entrepreneurs: Characteristics, drivers, and success factors", Journal of International Entrepreneurship 10.1 (2012): 50-69.

[12] Pavlov T, Balli B, Predojevic-Despic J, Milutinovic S (2013), "Transnational networks, transnational entrepreneurship and the role of state: The cases of Serbia and Albania”, ISBN 978-8686001-62-7, Group 484 Tutin, Serbia ,pp148.

[13] Portes, A.(1995) , "Transnational communities: Their emergence and significance in the contemporary world system, In Keynote Address 19th Annual Conference on the political economy of the World- System: Latin America in the world-economy. Working paper". Miami, FL: North-South Centre, University of Miami, 1995

[14] Portes, A., Guarnizo, L. E., \& Haller, W. J. (2002), "Transnational entrepreneurs: An alternative form of immigrant economic adaptation", American Sociological Review, 278-298.

[15] Quirke. E.,Potter.R.B.,Conway.D.,(2009), "Transnationalism and the Second-Generation Caribbean Community in Britain", University of Reading; Geographical Paper No. 187

[16] Rogerson, J. and Mushawemhuka, W.J.(2015), "Transnational entrepreneurship in the Global South: evidence from Southern Africa", African Journal of Business Management, Sep 23, Vol.5(21), pp.8458-8469, 2015

[17] Saxenian, A.(2002), "Transnational communities and the evolution of global production networks:The cases of Taiwan, China and India, Industry and Innovation", 9, 183-202, 2002

[18] Saxenian, A. \& Hsu, J.-Y. (2001), "The silicon valley - Hsinchu connection: Technical communities and industrial upgrading, Industrial and Corporate Change", 10(4), 893-920, 2001.

[19] Sequeira M. Jennifer, Jon C. Carr and Abdul A. Rasheed (2009), "Transnational Entrepreneurship: Determinants of Firm Type and Owner Attributions of Success", Entrepreneurship Theory and Practice, 33 (5), 1023-44. Shane, S 2009.

[20] Vertovec, Steven (1999), "Conceiving and researching transnationalism", Ethnic and racial studies 22.2 (1999): 447-462.

[21] Vertovec, S (2004), "Trends and impacts of migrant transnationalism", (WP- 04-03), Oxford, U.K.: Centre on Migration, Policy and Society, 2004

[22] Wang, Q., \& Liu, C. Y. (2015), "Transnational activities of immigrant-owned firms and their performances in the USA" Small Business Economics, 44(2): 345-359.

[23] Windsor. G. (2015), "Highly skilled migration and the promotion of entrepreneurship in the UK", Loughborough University Institutional Repository.

[24] Wong, Lloyd L., and Michele Ng (2002), "The emergence of small transnational enterprise in Vancouver: The case of Chinese entrepreneur immigrants", International Journal of Urban and Regional Research 26.3 (2002): 508-530.

[25] Yeung, H (2002), "Entrepreneurship in international business: An institutional perspective", Asia Pacific Journal of Management, 19(1), 29-61, 2002. 